\title{
Venöz tromboembolizm tanımı ve fizyopatolojisi
}

\section{Definition and pathophysiology of venous thromboembolism}

\author{
E. Ertuğrul Şener ${ }^{1}$, İsmail Daldal ${ }^{2}$ \\ ${ }^{1}$ Gazi Üniversitesi Tıp Fakültesi, Ortopedi ve Travmatoloji Anabilim Dalı, Ankara \\ ${ }^{2}$ Sağlık Bakanlığı, Sakarya Üniversitesi Eğitim ve Araştırma Hastanesi, Ortopedi ve Travmatoloji Anabilim Dalı, Adapazarı, Sakarya
}

\begin{abstract}
Venöz tromboembolizm (VTE), kalça ve diz artroplastilerinde, büyük kemik kırıkları ve tümör cerrahisinde ameliyat döneminde ortaya çıkan, morbiditeyi, mortaliteyi ve hastanın sağlık maliyetlerini arttıran önemli fakat önlenebilir bir problemdir. Cerrahlar, uzun zamandır bu önemli komplikasyondan korunmaya çalışmaktadırlar. Korunmayı sağlamak için öncelikle oluş mekanizmasının aydınlatılması gerekir. Son yıllarda büyük adımlar atılmasına rağmen, VTE'nin karmaşık oluş mekanizması henüz tam olarak açıklanamamıştır. Bu nedenle güncel profilaksi rehberleri sorunu önlemekte başarısız kalmaktadır.
\end{abstract}

Anahtar sözcülkler: venöz tromboembolizm; derin ven trombozu; pulmoner emboli; profilaksi; ameliyat dönemi komplikasyonlar; artroplasti
Venous thromboembolism (VTE) remains a major problem that increases morbidity, mortality and health costs in hip and knee replacement surgery, major bone fractures and oncologic surgery which emerges during the perioperative period and is a preventable perioperative complication. Surgeons have been trying to avoid this complication for a long period of time. The mechanism must be understood clearly in order to avoid this complication. Although major steps have been taken in defining the complex pathogenesis of VTE in recent years, the mechanism has not been explained yet. Therefore, current prophylaxis guidelines fail to prevent this complication.

Key words: venous thromboembolism; deep vein thrombosis; pulmonary embolism; prophylaxis; perioperative complications; arthroplasty

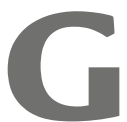

enellikle asemptomatik olarak seyreden derin ven trombozunu (DVT) ve mortal seyredebilen pulmoner embolizmi (PE) kapsayan bir terim olan venöz tromboembolizm (VTE), ameliyat döneminde morbiditeyi, mortaliteyi ve hastanın sağlık maliyetlerini arttıran önemli bir problemdir. Yaklaşık bir milyon kadın üzerinde yapılan bir çalışmada, hastanede yatarak cerrahi işlem geçiren kadınların, ameliyat sonrası altı hafta içerisinde VTE nedeni ile tekrar hastaneye başvuru sayısının, ameliyat olmayanlara göre 70 kat fazla olduğu saptanmıştır. ${ }^{[1]}$ Bazı çalışmalarda, hastane ile ilişkili ölümlerin \%10'unda VTE'nin sorumlu olduğu tahmin edilmiş ve VTE'ye bağlı mortalite oranlarının, meme kanseri, kalp krizi ve serebrovasküler nedenlere bağlı ölümlerden daha yüksek olduğu gözlenmiştir. ${ }^{[2,3]} \mathrm{Hem}$ hastanede yatış sürelerinin, hem de geçirilen operasyonların VTE riskini arttırdığı öngörülmekle birlikte, geçirilen major cerrahilerin VTE açısından tek başına en önemli risk faktörü olduğu bildirilmiştir. ${ }^{[4]}$ VTE'nin gerçek insidansı tam olarak bilinmemekle birlikte, hastanede cerrahi işlem geçiren hastaların \%25'inden fazlasının VTE'den etkilendiği ve VTE açısından en riskli cerrahi tiplerinin diz ve kalça artroplastisi, büyük kemik kırıkları ve kanser cerrahisi gibi majör cerrahiler olduğu bildirilmiştir. ${ }^{[5]}$ Gerçek insidansın tam olarak bilinmemesinin nedeni, asemptomatik VTE'lerin saptanmasındaki zorluklar ve ameliyat sonrası kısa ve/veya uzun dönemdeki VTE insidansının çoğunun çalışmada göz ardı edilmiş olmasıdır. Gerçekte, hastane ilişkili ölümlerin $\% 70$ kadarı PE nedenlidir ve bu tanı çoğu zaman ancak otopsi ile doğrulanabilir.

VTE komplikasyonlarını azaltmaya yardımcı olmak amacıyla hazırlanan Amerikan Göğüs Hekimleri Birliği VTE Profilaksi Rehberi (AT9) ve Amerikan Ortopedik Cerrahlar Akademisi (AAOS) VTE Profilaksi Rehberi gibi güncel kılavuzlar dünya çapında kabul edilip VTE profilaksisinde cerrahlar tarafindan kullanılmasına

- İletişim adresi: Prof. Dr. E. Ertuğrul Şener, Gazi Üniversitesi Tıp Fakültesi Ortopedi ve Travmatoloji Anabilim Dalı, 065100, Beşevler, Ankara Tel: 0312 - 2025526 e-posta: ertugrul_sener@yahoo.com

- Geliş tarihi: 22 Șubat $2019 \quad$ Kabul tarihi: 6 Ağustos 2019 
rağmen ${ }^{[6,7]}$, ne yazık ki son 20 yılda VTE'ye bağlı sorunların önlenmesi konusunda bir ilerleme kaydedilememiştir. Ayrıca, VTE için kullanılan güçlü profilaksi ajanlarının, VTE insidansını düşürürken, cerrahi sırasında ve cerrahi sonrasında gelişen kanama eğilimi, yara yeri sorunları ve enfeksiyona zemin hazırlama gibi ciddi olumsuz etkilerini de göz önünde bulundurmak gerekir. Hekimlerin çoğu tarafından kabul edilip VTE profilaksisinde kullanılan güncel kılavuzlar, cerrrahi sonrası kanama, enfeksiyon riski ve diğer sorunlar nedeniyle hastaya özel değişikliklere uğrayabilmektedir. VTE fizyopatolojisine yönelik çok önemli çalışmalar sürdürülmekte olmasına karşın, henüz fizyopatoloji net olarak anlaşılamamıştır.

\section{PATOFIZYOLOJi}

\section{Histolojik Değerlendirme}

Arteriyel trombozun aksine, henüz VTE mekanizması net olarak anlaşılamamıştır. Ancak, venöz trombüsün ven içindeki oluşum yeri ve büyüme aşamaları histolojik olarak net bir şekilde dokümante edilmiştir (Şekil 1). İntravasküler trombüs histolojik olarak iki tipe ayrilır: 1) primer olarak trombositlerden, arteriyel sistemin yüksek akımında oluşan "beyaz trombüs", 2) trombositlerin yanında, önemli ölçüde eritrosit ve fibrin içeriğine sahip venöz sistemin düşük akım hızında oluşan "kırmızı trombüs".

Trombüs yapısının içinde histolojik olarak eritrositfibrin karışımı kırmızı bölümler ve trombosit-nötrofil karışımı beyaz bölümler bulunur. Bu bölgeler laminalar şeklinde tabakalaşmıştır ve "Zahn çizgileri” adını alır. Kırmızı bölümler trombüsün ilk oluşum aşamasında önemli rol oynarken, beyaz bölümler oluşan kırmızı bölümlere bağlanarak trombüsün büyüyüp gelişmesine neden olur.

\section{Venöz Trombogenez}

Venöz trombüs, daima kan akımının yavaşladığı ven kapakçıklarının boyun bölgesinde gelişir. 1800’lü yılların ortalarına kadar kan pıhtısı oluşumu ile ilgili ilkel mikroskoplarla yapılan çalışmalar neticesinde bazı teoriler öne sürülmüştü. Mikroskopların gelişmesi ile, 1840'lı yılların ikinci yarısında Virchow, öncekilerden farklı olarak DVT oluş mekanizmasındaki anlayışımızın temelini oluşturan iki önemli gözlem yapmıştır. Birincisi; trombüs ve emboli kitlesinin içinde bulunan lökositlerin, eskiden inanıldığı gibi, venleri çevreleyen yumuşak dokudan değil, dolaşımdaki kandan kaynaklandığıdır. Virchow, ikinci olarak; trombüsün ilk oluştuğu ve damar duvarına yapıştığı lokalizasyonun ven kapakçık bölgesinde olduğunu, histolopatolojinin temelini oluşturan kitaplarında çok net çizimlerle anlatmıştır.
Sonrasında, 1970'li yıllarda Sevitt, Virchow'un çalışmalarını daha da ileriye götürerek, trombüsün kapakçık bölgesindeki hipoksik veya nekrotik pariatel endotel tabakasına yapıştığını belirtmiştir. ${ }^{[8,9]}$

\section{Venöz Staz}

Normal periferik venöz dolaşım temel olarak iki komponentten oluşur: 1) sürekli laminar akım ve 2) kas kasılması ve venöz kapakçıkların etkili olduğu pulsatif akım (Şekil 2).

Laminar akım, sol ventrikül kasılması sonrası arteriollerdeki elastik geri çekilmenin etkisiyle kapiller yatağa geçen kan akımının düşük başınçla sağ atriuma venöz sistem aracılığıyla geçişini açıklar. Normal venöz basıncın ve kapiller mikrovasküler direncin artması laminar akım üzerine olumsuz etkilidir. Yine, özellikle ortopedik cerrrahi sırasında kullanılan turnikeler, laminar akımı geçici olarak durdurur.

Kas kontraksiyonları ile ven duvarında mekanik olarak oluşturulan basınç artışı, periferik venöz kanın sağ atriuma ilerlemesini sağlayan ve laminar akıma yardımcı olan sistem, "pulsatif akım" olarak isimlendirilir. Pulsatif akımın optimum çalışabilmesi için, valf mekanizması olarak işleyen ven kapakçık sistemi büyük önem taşır. Pulsatif akım, yatak istirahati ve genel anestezi gibi durumlarda kesintiye uğrar.

Sürekli laminar akım, temel olarak damar içindeki protrombotik ve antitrombotik dengenin sürdürülmesini sağlar. Ancak, pulsatif akımın düzgün çalışmadığı durumlarda, bu akım DVT'nin geliştiği yer olan venöz kapakçık sisteminin boyun bölgesinde etkisizdir. Bir başka deyişle, DVT'nin başlangıç yeri olan venöz kapakçık ceplerindeki kan akımını, sadece düzgün çalışan bir pulsatif akım sağlayabilir.

\section{Ven Kapakçık Hipoksisi Tezi ve Endotel Hasarı}

"Virshow triadı" olarak literatürde benimsenip genel kabul gören "venöz staz, koagulopati ve endotel hasarı" üçlemesinin, aslında DVT patogenezini açıklamadığı yönünde, yakın zamanlı ciddi çalışmalar ve eleştiriler vardır. ${ }^{[10-12]}$ Hattâ Malone ve ark. ${ }^{[13]}$, "Virshow triadı" kavramının literatürden tamamen kaldırılması gerektiğini, çünkü DVT patogenezinin araştırılması önünde engel teşkil ettiğini ve bu ortaya çıkarılan konsensus modelin Virchow'un yazılarında bulunmadığı ve başka yazarlarca çarpıtıldığını belirtmektedirler. Virchow yazılarında "hiperkoagulopati" değil "kan birleşim ürünleri" terimini, "staz" değil "kan akım faktörlerini” kullanmasına rağmen, modern literatürün halen Virshow'u yanlış anladığı belirtilmektedir. Sonuç olarak; Virshow triadı DVT'nin etkilerini açıklayabilmekte, ancak patofizyolojiyi tam olarak açıklayamamaktadır. 


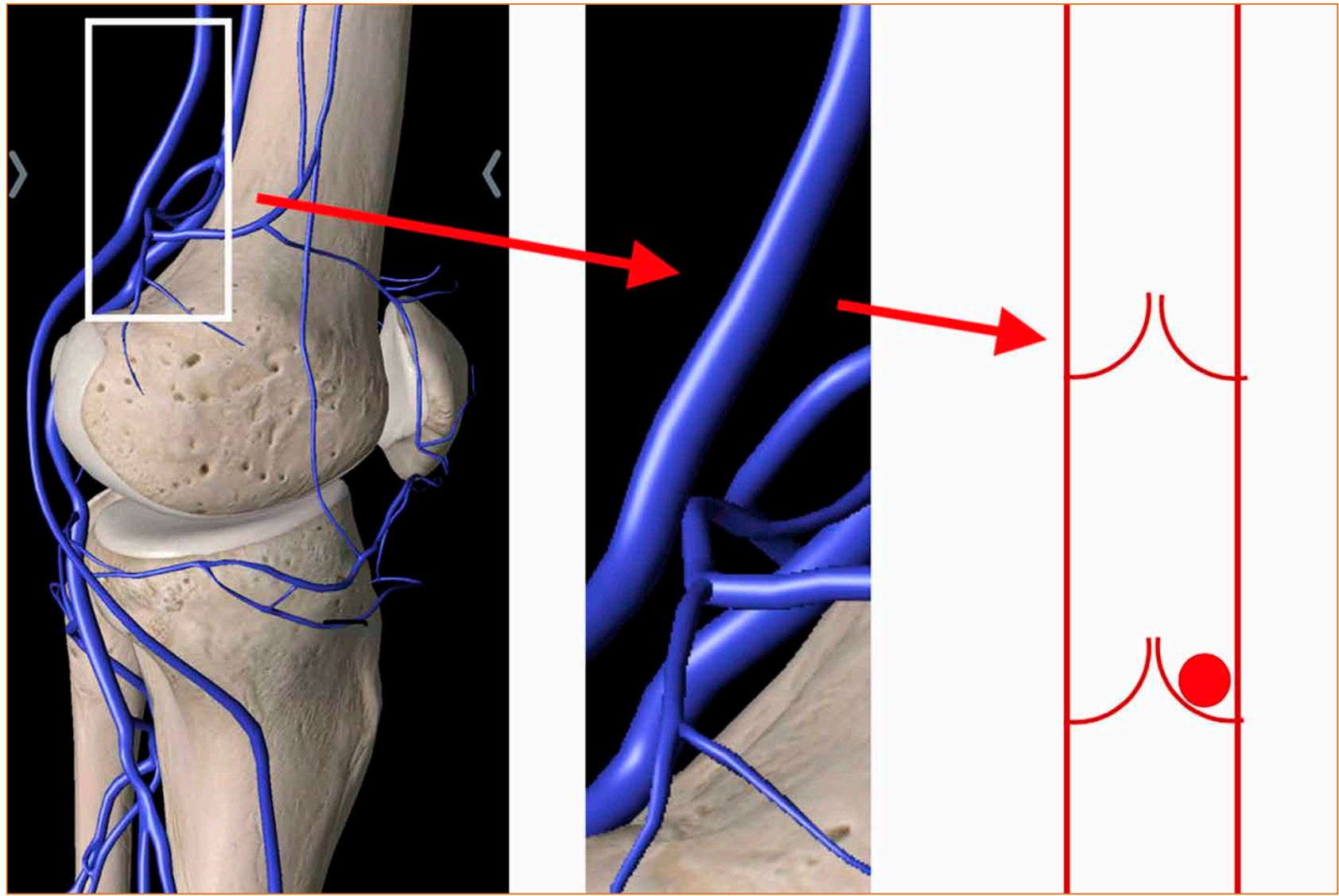

Şekil 1. DVT oluşum yerinin şematik çizimi.

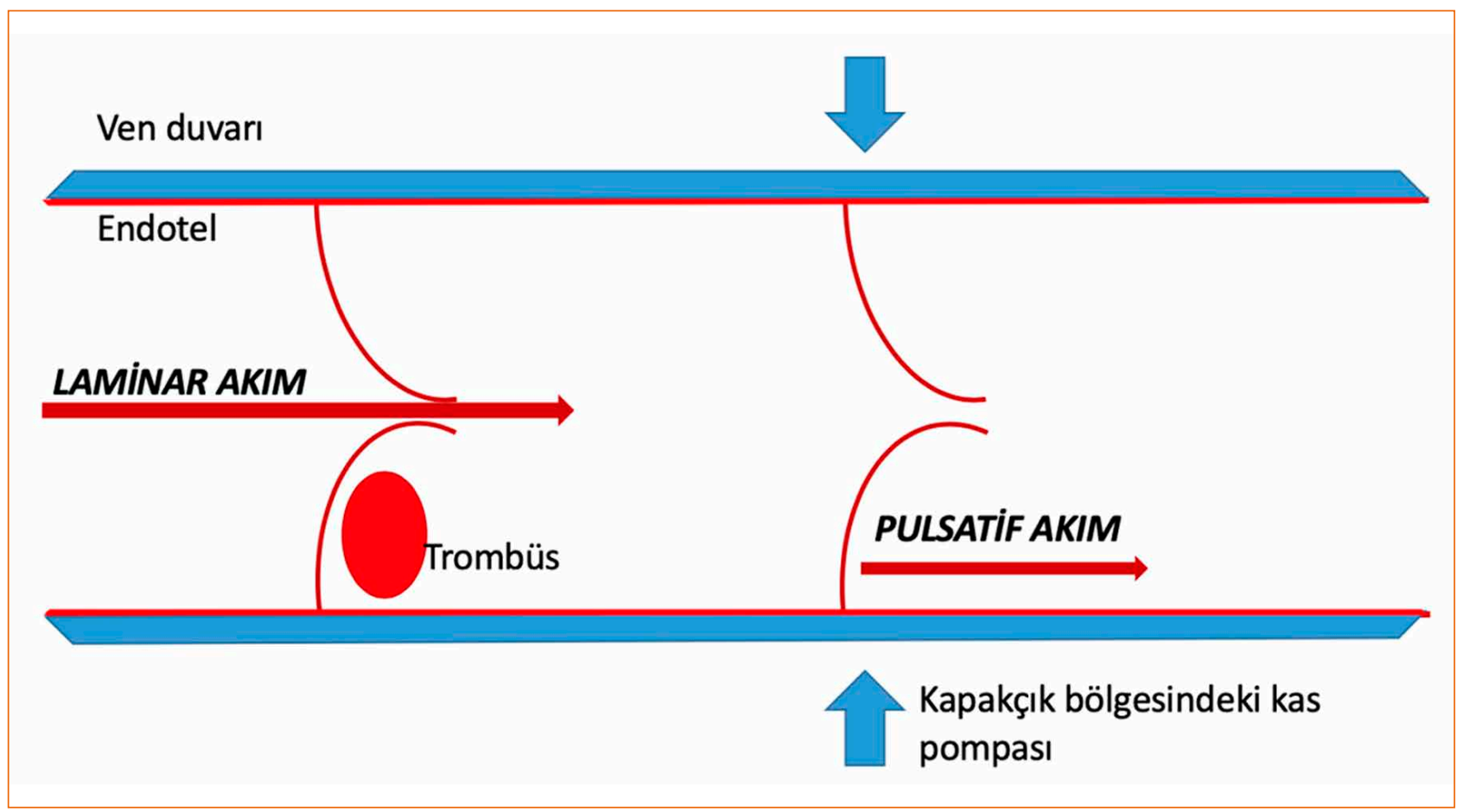

Şekil 2. Laminar ve pulsatif akımın şematik çizimi. Venöz kapakçık bölgesindeki kas kontraksiyonları (mavi oklar), pulsatif akımın oluşmasını ve böylece kapakçık boyun bölgesindeki kan akışını sağlar. 
Şekil 1'de gösterildiği üzere, DVT oluşum yeri venöz kapakçıklardaki sinuslardır ve bu oluşum, venöz kapakçık hipoksisi tezi ile açıklanabilir. Normalde ven, endotel duvarıyla karşılaştırıldığında, venöz valf endoteliyal hücre yüzeylerinden daha fazla miktarda trombomodülin ve protein $C$ gibi antikoagülan proteinler salgılar. ${ }^{[14]}$ Pulsatif akımın bozulduğu durumlarda sinuslarda kan akımı sağlanamaz ve venöz valf endoteliyal hücrelerinin beslenmesi bozulur. Bu özelleşmiş endotel bölgesindeki hipoksi ve sonrasında gelişen inflamasyon sonucu, bu bölgeden salgılanan antikoagülan proteinler "aşağı-regüle" (downregulated) olurken doku faktörü (TF) ve von Willebrand faktör (vWF) gibi prokoagülanlar "yukarı-regüle" (upregulated) olur.[15-17] Sonuç olarak, lokal prokoagülan-antikoagülan dengesi bozulur ve trombogenezis aktive edilir.

Hipoksi ve inflamasyon sonucu aktive olan venöz valf endoteliyal hücrelerinden salgılanan selektinler, monositleri, nötrofilleri ve güçlü bir prokoagülan olan TF'yi aktive eder. Kanda eş zamanlı olarak, vWF'den daha yapışkan ve trombofilik olan ul-vWF (unusually large Von Willebrand Factor) gözlenmeye başlar ve olay yerine daha fazla nötrofil ve trombosit gelir. Sonuçta oluşan kısır döngü ile birlikte, esas olarak TF ekstrinsik kaskadın tetiğini çeker, trombin oluşumu ve fibrinojenin fibrine dönüşümü gerçekleşir. Trombüs kitlesi büyüdükçe, trombosit aktivasyonu ve degranülasyonu sırasında daha fazla ul-vWF ve P-selektin salınır. Ul-vWF'nin kandan uzaklaştırılması için ADAMTS 13 enziminin moleküler uzaması gerekir ve sonuçta bu enzim ekspresyonu bozulmuş olur. ${ }^{[18,19]}$

\section{SONUÇ}

Venöz tromboembolizm, kalça diz artroplastisi, büyük kemik kırıkları ve tümör cerrahisinde, ameliyat sırasında halen ortopedistlerin korkulu rüyası olmaya devam etmektedir. Mortalitesi ve morbiditesi yüksek olan VTE'den korunmak ve etkin profilaksi kılavuzlarını geliştirebilmek için, oluş fizyopatolojisinin tam olarak açıklanması gerekir. Bu amaca yönelik çalışmalar henüz devam etmekte olup, ancak netlik sağlandıktan sonra korunma ve tedaviye yönelik daha etkili yöntemler geliştirilecek ve pratik uygulamalara geçilebilecektir.

\section{KAYNAKLAR}

1. Sweetland S, Green J, Liu B, Berrington de Gonzales A, Canonico M, Reeves G, Beral V; Million Women Study collaborators. Duration and magnitude of the postoperative risk of venous thromboembolism in middle aged women: prospective cohort study. BMJ 2009;339:b4583. Crossref

2. Gordon RJ, Lombard FW. Perioperative venous thromboembolism: A review. Anest Analg 2017;125(2):40312. Crossref
3. Raskob GE, Angchaisuksiri P, Blanco AN, Buller H, Gallus A, Hunt BJ, Hylek EM, Kakkar A, Konstantinides SV, McCumber M, Ozaki Y, Wendelboe A, Weitz JI; ISTH Steering Committee for World Thrombosis Day. Thrombosis: a major contributor to global disease burden. Arterioscler Thromb Vasc Biol 2014;34(11):2363-71. Crossref

4. Heit JA, Silverstein MD, Mohr DN, Petterson TM, Lohse CM, O'Fallon WM, Melton LJ 3rd. The epidemiology of venous thromboembolism in the community. Thromb Haemost 2001;86(1):452-63. Crossref

5. Caprini JA. Risk assessment as a guide to thrombosis prophylaxis. Curr Opin Pulm Med 2010;16:448-52. Crossref

6. MacLean S, Mulla S, Akl EA, Jankowski M, Vandvik PO, Ebrahim S, Mcleod S, Bhatnagar N, Guyatt GH. Patient values and preferences in decision making for antithrombotic therapy: a systematic review: Antithrombotic Therapy and Prevention of Thrombosis, 9th ed: American College of Chest Physicians Evidence-Based Clinical Practice Guidelines. Chest 2012;141(2 Suppl):e1S-e23S. Crossref

7. American Academy of Orthopaedic Surgeons. Preventing venous thromboembolic disease in patients undergoing elective hip and knee arthroplasty. Evidence-based guideline and evidence report. Rosemont, IL: AAOS; 2011. http:// www.aaos.org/research/guidelines/VTE/VTE_full_guideline. pdf Erişim: 25 Aralık 2018

8. Sevitt S. Organization of valve pocket thrombi and the anomalies of double thrombi and valve cusp involvement. $\mathrm{Br}$ J Surg 1974;61(8):641-9. Crossref

9. Sevitt $S$. The structure and growth of valve pocket thrombi in femoral veins. J Clin Pathol 1974;27(7):517-28. Crossref

10. Malone PC, Agutter PS. The aetiology of deep venous thrombosis. QJM 2006;99(9):581-93. Crossref

11. Chung I, Lip GYH. Virchow's triad revisited: blood constituents. Pathophysiol Haemost Thromb 2003-2004;33(5-6):449-54. Crossref

12. Bagot CN, Arya R. Virchow and his triad: a question of attribution. Br J Haematol 2008;143(2):180-90. Crossref

13. Malone PC, Agutter PS. Deep venous thrombosis: The valve cusp hypoxia thesis and its incompatibility with modern orthodoxy. Med Hypotheses 2016;86:60-6. Crossref

14. Brooks EG, Trotman W, Wadsworth MP, Taatjes DJ, Evans MF, Ittleman FP, Callas PW, Esmon CT, Bovil EG. Valves of the deep venous system: an overlooked risk factor. Blood 2009;114(6):1276-9. Crossref

15. Mackman N. New insights into the mechanisms of venous thrombosis. J Clin Invest 2012;122(7):2331-6. Crossref

16. Williams MR, Azcutia V, Newton G, Alcaide P, Luscinskas FW. Emerging mechanisms of neutrophil recruitment across endothelium. Trends Immunol 2011;32(10):461-9. Crossref

17. Calabro P, Gragnano F, Golia E, Grove EL. von Willebrand Factor and Venous Thromboembolism: Pathogenic Link and Therapeutic Implications. Semin Thromb Hemost 2018;44(3):249-260. Crossref

18. Lopez JA, Chen J. Pathophysiology of venous thrombosis. Thromb Res 2009;123(Suppl 4): S30-4. Crossref

19. Pepin M, Kleinjan A, Hajage D, Büller HR, Di Nisio M, Kamphuisen PW, Salomon L, Veyradier A, Stepanian A, Mahe I. ADAMTS-13 and von Willebrand factor predict venous thromboembolism in patients with cancer. J Thromb Haemost 2016;14(2):306-15. Crossref 